\title{
СУММА МЕТОДОЛОГИИ
}

Современная политическая наука. Методология /

Фтв. ред. Ф.В. Гаман-Голутвина, А.И. Никитин. М.: Аспект Пресс,

2๑19.776 с.

Современная политическая наука сложная и динамически развивающаяся система, функционирование которой требует не только адекватной организационной структуры и гибкого компетентного управления, но и специфических инструментов развития. Применительно к последнему речь прежде всего идёт о методологическом обосновании, без которого невозможен эффективный анализ, обеспечивающий осмысление новых - порой сверхсложных в современных условиях - объектов.

В работе «Рассуждение о методе, чтобы хорошо направлять свой разум и отыскивать истину в науках» (1637) Рене Декарт сформулировал важнейший принцип исследовательской деятельности: «Если воздерживаться от того, чтобы принимать за истинное что-либо, что таковым не является, и всегда соблюдать порядок, в каком следует выводить одно из другого, то не может существовать истин ни столь отдаленных, чтобы они были недостижимы, ни столь сокровенных, чтобы нельзя было их раскрыть» [Декарт 1989: 261].

Данное утверждение зафиксировало принципиальной важности эпистемологический принцип - императивом научного знания является требование методологически чёткого определения понятий, а также того, «Какими средствами и в каких пределах возможно решать даже неизвестные задачи» [Декарт 1989: 262]. Доказательством значимости данного подхода является, в частности, то, что «в русле именно этой традиции, тесно связанной с номинализмом, развивались столь непохожие друг на друга подходы, как метод восхождения от абстрактного к конкретному К. Маркса и идеально-типический метод М. Вебера» [Фурсов 2006: 35].

Адекватное понимание и прогнозирование политических процессов особенно в условиях плюрализации (и, как следствие, размытости, а зачастую и рыхлости критериев оценки) требует чёткой понятийной системы, которую следует рассматривать не только как conditio sine gua non (непременное условие) исследования, но и как его суть. Именно такой подход лежит в основе вышедшего в год 75-летия МГИМО МИД России труда под редакцией О.В. Гаман-Голутвиной и А.И. Никитина. Книга «Современная политическая наука: Методология» - первого в стране столь фундаментального издания по методологии политической науки, способствующего продвижению исследователей «по дороге в будущее-2.5» [Торкунов 2017].

Признанные авторитеты отечественных исследований (39 авторов, среди которых академики РАН А.В. Торкунов, А.А. Дынкин, Н.А. Симония, В.Г. Барановский, А.А. Кокошин; член-корреспондент РАН И.С. Семененко, профессора Т.А. Алексеева, А.Д. Воскресенский, М.М. Лебедева, М.М. Мчедлова, А.И. Соловьёв, Л.В. Сморгунов, М.В. Ильин, А.В. Крутских, Е.Б. Шестопал и др.) создали поистине энциклопедию (строго в греческом понимании «круг знания») современного политолога. Без преувеличения в данной книге реализован «принцип Дидро», ставший основанием Великой Энциклопедии XVIII века: 
привести знания в систему, «для людей, с которыми мы живём, и передать их людям, которые придут за нами: дабы труды минувших веков не были бесполезны для веков грядущих, дабы наши потомки, став образованнее, стали также добродетельнее и счастливее и чтобы мы могли умереть в сознании исполненного пред человечеством долга» [Энциклопедический словарь 1994: 879].

В условиях острой конкуренции за влияние, территории и ресурсы вряд ли можно согласиться с Дидро в том, что знания делают людей «добродетельнее и счастливее», но очевидно, что они позволяют понять причины происходящего, разработать стратегию и тактику эффективного развития. В условиях жёстко конкурентной (социальной, экономической, политической) среды необходимо не только иметь прочный теоретический фундамент, но методологически и инструментально быть готовым к новым вызовам. Такое понимание текущей реальности, как верно отметила в предисловии О.В. Гаман-Голутвина (инициатор и руководитель проекта), выдвигает на первый план вопрос о теоретико-концептуальных основаниях политической науки (С. 9).

В новых исторических условиях распространённое ранее упрощённое понимание методологии как науки о методах мышления теряет свою обоснованность. Из необходимого момента интеллектуальной деятельности в философии и обществоведческих дисциплинах методология современной политологии стала сложным компендиумом знаний. Серьёзный анализ невозможен без освоения «широкой панорамы классических и современных интеллектуальных политико-теоретических парадигм, выполняющих функцию методологических оснований политических исследований» (С. 10).

В рамках современной методологии как технологии мыслительной деятельности можно выделить два основных направления: критико-аналитический и проектноконструктивистский. В соответствии с первым интеллектуальная деятельность реализует рефлексию особого рода - критиче- скую и исследовательскую, перестраивая и развивая свой предмет, формулируя альтернативные (как внутренние акты М. Мамардашвили) подходы (С. 525) и предлагая новые техники исследования. Если в результате критической деятельности происходит «распредмечивание» понятий и иных дисциплинарных представлений, то в рамках проектно-конструктивистской ориентации осуществляется обратная процедура - «опредмечивание», то есть построение новых понятий и идеальных объектов. Всё это возможно в случае овладения всей совокупностью методологических парадигм.

Последние десятилетия были отмечены постепенной, но неуклонной разбалансировкой всей системы международных отношений. Произошедшие сдвиги, связанные в значительной степени с уничтожением суверенных государств на периферии капитализма (этот процесс ускорила «арабская весна») и с «сжиманием» суверенных прерогатив в его ядре, зеркальным образом отразились на ситуации в западных странах и в России [Пономарёва 2019: 168-169]. Отдельные явления в экономической, социальной, информационной, политической, военной сферах детерминировали глобальный кризис, который кардинально меняет образ старого мира и создаёт предпосылки для вызревания его нового качества. Что произойдёт в обозримом будущем: демонтаж глобального рынка «сверху» или его уничтожение силами «новых гуннов»? Какие «мегатренды мировой политики» [Мегатренды 2019] будет определять будущее? Произойдет ли «политическое усиление государства через его онтологическое ослабление» [Харкевич 2012] или дни этого исторического субъекта сочтены? Как России пройти «бутылочное горлышко» глобального кризиса, обрести мощь и сохранить самость в грядущем мире неогуманизма и секьюритизации? Дать максимально широкие и объективные ответы на эти и ряд других вопросов современной науки и практики невозможно без адекватно выстроенной методологии. Рецензируемое издание существенно облегчит решение этой задачи (как говорил выдающийся русский 
физиолог И.П. Павлов, «метод держит в руках судьбу исследования»), поскольку в нём представлена панорамная картина всех значимых парадигм и концепций.

«Социальная наука в силу своей природы не может претендовать на получение эмпирически безупречных, абсолютно объективных фактов. Её прогнозы могут носить сугубо вероятностный характер, ибо всегда оставляют за рамками анализа важнейшие, но не поддающиеся точному учёту и верификации явления социальной жизни. Прежде всего, речь идёт о таких явлениях, как ценности, привычки, неосознаваемые навыки поведения - обо всём том, что укладывается в понятие "иррационального” " [Цыганков 1995: 75-76]. Именно поэтому с особым вниманием и тщательностью необходимо подходить при политологических исследованиях к выбору теоретико-методологических концепций.

Профессионально изучая политическое развитие балканских стран, могу утверждать: объективный анализ событий, происходящих в регионе, который «на протяжении столетий был и остаётся ареной столкновения культур, религий, борьбы великих держав» [Вишняков, Пономарёва 2019: 108], невозможен без опоры на цивилизационную, культурологическую и элитоцентричную парадигмы, а также на неореализм и конструктивизм. Цивилизационный анализ позволяет выделить «глубинные факторы развития, архетипические черты и долговременные признаки» (С. 15), формирующие применительно к Балканам модель «нового прошлого», которая при определённом ракурсе служит доказательством цикличности региональной политики, зависимой от ритмов и волн политики мировой (С. 553-554).

Культурологическая модель, несмотря на свою принципиальную открытость и динамичность, даёт возможность определить степень влияния культуры, формируемых её паттернов на политику, и наоборот. Эту взаимосвязь чётко уловили В.Г. Федотова, С.В. Чугров и Н.Н. Федотова: «Культура и политика всё более не принадлежат независимым друг от друга областям реально- сти - культура подвергается политизации, а политика становится культурно зависимой. Двойственное отношение политики и культуры, состоящее в доминировании то одного, то другого начала, продолжает сохраняться, но всякое изменение политики требует новой политической культуры, а всякое стремление к изменению политики требует изменения культуры» (С. 405). Очевидно, что культурологическое видение не может иметь универсального характера, но «сам принцип ведущей роли культуры для политологии любого общества, безусловно, остается» (С. 405).

В условиях высокой конфликтности современного мира востребованной оптикой анализа становится конфликтологическая парадигма изучения мировой политики. В главе А.И. Никитина представлен обстоятельный разбор классической и современной литературы по данной теме; изложен современный взгляд относительно сущности, причин и факторов международных конфликтов; дана их классификация и типологизация; методы урегулирования конфликтов. С позиций данной парадигмы особенно детально рассмотрены вооружённые конфликты, технологии и методы их урегулирования, а также миротворческая деятельность. Дополнительную убедительность сообщает включённость автора в международные сети исследователей международных конфликтов [Никитин 2018; 2016].

Значимое место отводится в издании обсуждению интеграционной парадигмы в исследованиях мирополитических процессов (А.А. Байков), что актуализировано противоречивыми тенденциями в глобальной и региональной политике: интеграционные тренды развиваются порой параллельно с противоположными им. А.А. Байков представляет широкую панораму интеграционных подходов, включая освещение истоков интеграционной идеи; особенности теорий интеграции глобального и среднего уровней; альтернативы и вызовы классическим интеграционным теориям. Достоинством данного анализа является то, что автор методологически обобщает значи- 
тельный опыт эмпирического изучения многообразных интеграционных процессов.

Особо следует сказать о неореализме, или так называемом структурном реализме, представители которого «используют системный анализ международных отношений», в результате применения которого «взаимодействие разрозненных элементов приобретает новое качество» (С. 61). Автор данного раздела в книге А.В. Фененко акцентирует внимание на «революции» К. Уолтца, позволившей выделить три типа системных факторов, влияющих на поведение государств в международных отношениях. Bo-nервых, это базовые нормы, лежащие в основе конкретного международного порядка (например, принцип гегемонизма определяет роль США и НАТО в балканской политике). Во-вторых, это мирополитическая среда, которая определяет поведение отдельных его участников. B-mpeтьих, это роль системных регуляторов - механизмов, определяющих эволюцию конкретной системы международных отношений (C. 65). Применительно к Балканам неореализм оказывается необходимым условием объективного анализа, так как позволяет выявить, с одной стороны, место и роль региона в конкретной международной системе; с другой - понять логику поведения элитных групп отдельных стран.

Ocобое место в международно-политических исследованиях, в том числе в балканских штудиях, занимает конструктивистский подход, позволяющий исследовать многие явления не как индивидуальные акты, а как интерсубъектную структуpy, то есть систему взаимодействий людей, интересы и цели которых также являются социально значимыми феноменами. Кроме того, этот подход, ориентированный на «Точную историческую реконструкцию» [Dessler 1999: 129], на поиск «малых истин» и объяснение, «почему политический мир является таким, а не другим...» [Finnemore, Sikkink 2001: 394], раскрывает конкретные факторы своеобразия политики конкретной страны, группы лиц. Признанный авторитет в этом вопросе Т.А. Алексеева делает необходимое уточнение: «Конструкти- визм - не теория в широком смысле слова, а разделяемая совокупность исходных посылок, которые могут быть представлены как методология» (С. 297). И хотя с таким подходом согласны далеко не все, он представляется верным.

Рассмотрение деятельности политических элит (групп, корпораций, кланов) как инициаторов и важнейших факторов системных и режимных изменений является не только эвристически значимым направлением современной науки, но и крайне увлекательным занятием. Например, понять, почему кланы (на албанском фисы) внутри руководства частично признанной Республики Косово (группировки президента и премьера - Х. Тачи и Р. Харадиная) находятся в жёсткой оппозиции, но поддерживаются одними и теми же внешними игроками и ставят одни и те же цели, невозможно без опоры на элитоцентричную парадигму.

Глава, посвящённая данному вопросу, написана ведущим отечественным специалистом - O.В. Гаман-Голутвиной [GamanGolutvina 2007; 2008; 2009; 2013; 2018 ]. Её подход отличает понимание сложности ключевого концепта парадигмы: «Выступая в качестве объекта изучения целого ряда дисциплин, феномен элит существенно различен в качестве предмета исследования социальных наук» (С. 410). Однако эту концептуальную двойственность не следует рассматривать как некий ограничитель - наоборот, она расширяет эвристические возможности, позволяя сочетать различные подходы.

Элитоцентричная парадигма позволяет узнать, кто на самом деле обладает властью и каковы взаимоотношения между этими людьми, что имеет принципиальное значение для анализа современных политических процессов в любой стране мира. Поэтому «великий бунтарь американской социологии» [Хазин, Щеглов 2018: 399] Чарльз Райт Миллс, изучавший «могущественных людей», до сих пор остаётся едва ли не самым цитируемым её классиком. Его вердикт не утратил своей актуальности: «Под могущественными людьми мы, 
конечно, подразумеваем тех, кто имеет возможность осуществлять свою волю даже в том случае, когда другие сопротивляются ей. Никто, следовательно, не может быть по-настоящему могущественным, если он не имеет доступ к управлению важнейшими социальными институтами (государство, корпорации, армия), ибо власть подлинно могущественных людей заключается, прежде всего, в том, что они распоряжаются этими общественными орудиями власти» [Wright Mills 1956: 9].

Подводя итог краткому обзору лишь некоторых парадигм, следует отметить, что именно сочетание ряда методологических подходов даёт возможность исследовать предмет с разных сторон, рассмотреть не только фасад явления, но заглянуть «за кулисы», а значит, вскрыть истинные причины происходящего, выявить интересы главных игроков.
Дать развёрнутый анализ 800-страничного труда, включающего 33 главы, не представляется возможным. Убеждена: рецензируемое издание как компендиум совокупности методологического знания представляет несомненный интерес как для начинающего исследователя, так и умудрённого опытом.

В 1964 г. был опубликован философскофутуристический трактат С. Лема «Сумма технологии». Книга не только пережила десятки переизданий - она опередила время и предвосхитила многие научные направления. У «Современной политической науки» есть все основания повторить судьбу лемовского бестселлера и стать «Суммой методологии» для многих поколений учёных.

\section{Елена Пономарёва доктор политических наук}

\section{Список литературы}

Вишняков Я.В., Пономарёва Е.Г. Сербия на Балканах: изобретение «порохового погреба Европы» // Современная Европа. 2018. № 7. С. 108-121.

Декарт Р. Рассуждения о методе // Декарт Р. Сочинения: В 2 т. Т. 1. М.: Мысль, 1989. С. 250-296.

Мегатренды мировой политики и их развитие в XXI веке / Под ред. М.М. Лебедевой. М.: Аспект Пресс, 2019. 400 с.

Никитин А.И. Современный миропорядок: его кризис и перспективы // Полис. Политические исследования. 2018. № 6. С. 32-46. DOl:https://doi.org/10.17976/jpps/2018.06.03.

Никитин А.И. Новая система отношений великих держав XXI века: «концерт» или конфронтация? // Полис. Политические исследования. 2016. № 1. С. 44-59. DOl:https://doi.org/10.17976/jpps/ 2016.01.04.

Пономарёва Е.Г. По ту сторону водораздела // Вестник МГИМО-Университета. 2019. Т. 64. № 1. C. 168-173. DOI https://doi.org/10.24833/2071-8160-2019-1-64-168-173.

Торкунов А.В. По дороге в будущее-2.5. М.: Аспект Пресс, 2017. 648 с.

Фурсов К.А. Держава-купец. М.: КМК, 2006. 364 с.

Хазин М., Щеглов С. Лестница в небо. М.: РИПОЛ классик, 2018. 624 с.

Харкевич М.В. Политическое усиление государства через его онтологическое ослабление // Полис. 2012. № 5. С. 122-129.

Цыганков А.П. Современные политические режимы: структура, типология, динамика. М.: Интерпракс, 1995. 296 с.

Энциклопедический словарь Ф.А. Брокгауза и И.А. Ефрона. М.: Терра - Terra, 1994. Репринтное издание 1890. Т. 80.954 с.

Dessler D. Constructivism within a Positivist Social Science // Review of International Studies. 1999. Vol. 25. № 1. P. 129.

Finnemore M., Sikkink K. Taking Stock: The Constructivist Research Program in International Relations and Comparative Politics // Annual Review of Political Science. 2001. № 4. P. 394.

Wright Mills Ch. The Power Elite. Oxford: Oxford University Press, 1956. 423 p.

Gaman-Golutvina O. Political Elites in the USA under George W. Bush and Barack Obama: Structure and International Politics // Historical Social Research. 2018. Vol. 43. No. 4. P. 141-163. https://doi. org/10.12759/hsr.43.2018.4.141-163.

Gaman-Golutvina 0. Parliamentary representation and MPs in Russia: Historical retrospective and comparative perspective // Parliamentary Elites in Central and Eastern Europe. Recruitment and Representation / ed. by E. Semenova, M. Edinger, H. Best. Routledge, 2013. P. 241-260. 
Gaman-Golutvina O. Elites and Leadership in Russian Politics // The Ashgate Research Companion to Political Leadership / ed. by J. Masciulli , M.A. Molchanov , W.A. Knight. London: Routledge, 2009. P. 269-287.

Gaman-Golutvina O. Political Elites in the Commonwealth of Independent States: Recruitment and Rotation Tendencies // Comparative Sociology. 2007. Volume 6: Issue 1-2. DOI: https://doi.org/ 10.1163/156913307X208140.

Gaman-Golutvina 0 . The Changing Role of the State and State Bureaucracy in the Context of Public Administration Reforms: Russian and Foreign Experience // Journal of Communist Studies and Transition Politics. 2008. Vol. 24. No. 1. P. 37-53. doi.org/10.1080/13523270701840449.

\section{References}

(1994]. Enciklopedicheskij Slovar' F.A. Brokgauza i I.A. Efrona [Encyclopedic Dictionary of F.A. Brockhaus \& I.A. Efrona]. 1994. Moscow: Terra. Reprint 1890. Vol. 80. 954 p.

Dekart R. (1989). Rassuzhdeniya o metode [Discourse on Method]. In Dekart R. Sochineniya. V 2-h t. T. 1. Moscow: Think. P. 250-296.

Dessler D. (1999). Constructivism within a Positivist Social Science. Review of International Studies. Vol. 25. No. 1. P. 123-137.

Finnemore M., Sikkink K. (2001). Taking Stock: The Constructivist Research Program in International Relations and Comparative Politics. Annual Review of Political Science. No. 4. P. 391-416.

Fursov K.A. (2006). Derzhava-kupets [Power-merchant]. Moscow: KMK. 364 p.

Gaman-Golutvina 0. (2009). Elites and Leadership in Russian Politics. In: Masciulli J., Molchanov M.A., Knight W.A. (eds) The Ashgate Research Companion to Political Leadership. London. Routledge. P. 269-287.

Gaman-Golutvina 0. (2007). Political Elites in the Commonwealth of Independent States: Recruitment and Rotation Tendencies. Comparative Sociology. Vol. 6. No. 1-2. P. 136-157. DOI: https://doi.org/ 10.1163/156913307X208140.

Gaman-Golutvina 0. (2008). The Changing Role of the State and State Bureaucracy in the Context of Public Administration Reforms: Russian and Foreign Experience. Journal of Communist Studies and Transition Politics. Vol. 24. No. 1. P. 37-53. doi.org/10.1080/13523270701840449.

Gaman-Golutvina 0. (2013). Parliamentary representation and MPs in Russia: Historical retrospective and comparative perspective, In: Semenova E., Edinger M., Best H. (eds) Parliamentary Elites in Central and Eastern Europe. Recruitment and Representation. Routledge. P. 241-260.

Gaman-Golutvina 0. (2018). Political Elites in the USA under George W. Bush and Barack Obama: Structure and International Politics. Historical Social Research. Vol. 43. No. 4. P. 141-163. https:// doi.org/10.12759/hsr.43.2018.4.141-163.

Hazin M., Shcheglov S. (2018). Lestnitsa v nebo [Stairway to Heaven]. Moscow: RIPOL klassik. 624 p.

Kharkevich M.V. (2012). Politicheskoe usilenie gosudarstva cherez ego ontologicheskoe oslablenie [Political strengthening of the state through its ontological weakening]. Polis. No. 5. P. 122-129.

Lebedeva M.M. (ed) (2019). Megatrendy mirovoj politiki i ikh razvitie v XXI veke [Megatrends of world politics and their development in the XXI century]. Moscow: Aspekt Press. 400 p.

Nikitin A. (2016). Novaya sistema otnosheniy velikhih derzhav XXI veka: kontsert ili konfrontatsiya? Polis. Politicheskie issledovaniya. No. 1. P. 44-59.

Nikitin A. (2018). Sovremennyi miroporyadok: ego krizis i perspektivy. Polis. Politicheskie issledovaniya. No. 6. P. 32-46. DOl:https://doi.org/10.17976/jpps/2018.06.03.

Ponomareva E.G. (2019). On the over side of watershed. Vestnik MGIMO-Universiteta. Vol. 64. No. 1. P. 168-173. DOI https://doi.org/10.24833/2071-8160-2019-1-64-168-173.

Torkunov A.V. (2017). Po doroge $v$ budushhee-2.5 [On the way to the future-2.5.]. Moscow, Aspekt Press. 648 p.

Tsigankov A.P. (1995]. Sovremennye politicheskie rezhimy: struktura, tipologiya, dinamika [Modern political regimes: structure, typology, dynamics]. Moscow: Interpraks. 296 p.

Vishnyakov Y.V. Ponomareva E.G. (2018). Serbiya na Balkanakh. Izobretenie «porokhovogo pogreba Evropy" [Serbia in the Balkans: The Invention of "Europe's Powder Magazine"]. Sovremennaya Evropa. No. 7. P. 108-122.

Wright Mills Ch. (1956). The Power Elite. Oxford: Oxford University Press. 423 p. 